\title{
Erratum
}

Vol 8, \#3

\section{MEASURING PATHOLOGICAL GAMBLING IN CHILDREN: THE CASE OF THE U.K.}

Page 280, 1st paragraph should read as follows:

Griteria 2 (tolerance), 3 (withdrawal) and 6 (lies/deception) were the best predictors of "probable pathological" gambling for this sample. Criteria 1 (preoccupation), 4 (escape) and 7 (illegal acts) were next in their discriminating ability. Criteria 8 (family/education) and 9 (bailout) discriminated less effectively; and criterion 5 (chasing) was common among all the gamblers (see discussion). However, all items were significant predictors of "probable pathological" gambling in the children studied $(\mathrm{p}<.001)$. 